rotation. They are based upon a hydrodynamical investigation by Dr. Jukowsky, showing that in a liquid globe of which the angular rate of rotation increases from centre to surface according to a certain law, superficial currents set from the poles towards the equator, but take the opposite direction if the rotation be accelerated from surface to centre. These theoretical deductions have been experimentally verified by $\mathrm{M}$. Belopolsky. A new criterion is thereby furnished as to the fashion of the sun's internal rotation. For both Spörer and Carrington have recognised that the motion of spots in latitude tends, on the whole, poleward ; while the closing in towards the equator, with the progress of each epoch of disturbance, of the zone in which spots, faculæ, and prominences chiefly manifest themselves, is a well-recognised feature of periodical solar activity. This zonal movement is held to depend upon currents at considerable depths, but the drift of individual spots upon surface-flow; hence the sun's system of circulation is such as to indicate, according to Jukowsky's theory, rotation accelerated towards the centre.

The cause of this inequality is found by M. Belopolsky in the non-homogeneous character of the solar globe. Assuming that the variations of its density conform to the law adopted by $M$. Roche for the terrestrial spheroid $\left(\rho=\rho_{\mathrm{o}}\left(\mathrm{I}-\beta r^{2}\right)\right)$, it follows that gravity must attain a maximum at a certain depth below the surface (this depth, in the case of the earth, is $1 / 6$ th of the radius). Under these circumstances the rate of rotation and amount of polar compression of successive solar strata must vary with gravity, and in the same sense. It is, moreover, highly probable that gravity and angular velocity will attain a maximum simultaneously. The ensuing frictional acceleration of the superimposed slower-moving layers is so conditioned as to lead directly to a law of surfacerotation identical with the empirical formula arrived at by Spörer from observation solely $(\xi=\omega+a \cos \phi)$.

The minimum period of rotation for an interior solar shell, computed according to the foregoing hypothesis, is $2 I^{\circ} 3$ days; the longest observed period for any part of the superficial globe is 27.5 days The mean of the two (24.4 days) differs very little from the period of 24.5 days deduced by Hornstein from magnetic observations. It is pointed out that Faye's rationale of the peculiar character of the sun's rotation implies for an inner nucleus the improbably short period of $2 \cdot 2$ to 3 days.

\section{EDUCATION IN THE UNITED STATES ${ }^{1}$}

$\mathrm{THE}$ work of education in the United States of America, as delineated in the Commissioner's report, is making steady progress and keeping pace with the great increase of population in that country, where are 266 cities with an average of 40,000 inhabitants, and a lowest limit of 7500 . Various States are able to perceive that a more efficient course of education provided in them for the next generation is one of the greatest attractions to those earnest striving settlers who are the backbone of a growing country; and money and energy in increasing amounts are devoted to the purpose. The successful guidance of these powers to desired results depends largely upon the selection of capable district superintendents who will provide for the more careful selection and improvement also of teachers, and introduce the best methods and the best facilities of instruction; thus making common to the many what would have been confined to the extra intelligent few. The first use, therefore, to be made of liberal money votes is the provision of high-class inspectors, who can be secured only by higher salaries. One important duty of these officers arises from the system of establishing schools in every I "Report of the Commissioner of Education for the Year $188_{3}-84$."
(Washington, Government Printing Office, $188_{5}$.) district being so perfect in all of the United States, that in Connecticut, for example, there are 158 school districts which have less than eight scholars in attendance during the year, and one case is quoted, not as being by any means unparalleled, of a school having only four scholars during the year, and for three months having one only, whose education consequently cost the district 60 dollars. In such circumstances the State inspectors can recommend the consolidation of several of these school districts into one. Where this cannot be done, it is not likely that an efficient, qualified teacher can be secured for each. Yet rather than this scattered population should grow up half taught, the New York superintendent of popular instruction recommends that a sufficient salary shall be made good out of State or general Government funds. It is the more necessary to meet this difficulty as population is not everywhere increasing. In Maine, for example, population has decreased, and the number of school districts has been reduced already.

In Massachusetts a greater number of scholars than the whole number of the school population (from 5 years of age to I5) were enrolled; but, on the other hand, Maryland and Virginia showed only 28 and $29 \frac{1}{2}$ per cent. attending, and what reports could be gained from Louisiana showed only 19 per cent. enrolled, and not above 13 per cent. attending. Of course, in such a State, there is the double difficulty of getting the coloured population to school and of raising the money to pay for it ; poverty standing in the way of fair remuneration of teachers as much as the lazy ignorance of the blacks in that of regular attendance. Naturally half-day sessions have suggested themselves as being economical in every way, requiring only half the staff of teachers, and half the schools and school-furniture. But a danger in this system is lest the teacher should be overworked; and, where he is able to do so greatly increased work, it is fairly recommended that his salary should be increased accordingly. A great variety of work therefore presents itself to the inspectors, and much discretion and knowledge will be required to meet all emergencies.

It is easy to see that no New World organisations or ambitions are any match for the evils of population bred down to the point of a hard struggle for existence. These evils are developing in America as fast as they did in ancient cities. Truancy is increasing, and many children never attend school even in such a city as Providence, R.I. New York experience acquits employers of labour of any mischievous influence in the matter. It is curious to note that while in England charitable funds have been diverted gradually to the education of the more promising children, and School Boards have had intrusted to them the unpromising residuum, in American great cities the public schools take in all the former, while the benevolent are urged to take up the work of teaching the latter, for whom the regular course is too advanced. Free education, approved by certain States, can be more easily adopted in such a state of thing:, where the large ratepayers get large advantages, than in a country like ours, where payment made and advantage to be gained would be in exactly inverse ratio.

A very large proportion of the pupils in the primary schools are of the ages of 8 and 9 , and the number who pass on to the secondary schools is about 40 per cent.; but not I in 12 of these reaches the higher standards of the secondary schools. Since also 60 per cent. never get beyond the elementary schools, the report urges how needful it is that the education given in these schools should be as complete in itself as possible, and not merely a preparatory step towards the "grammar" or secondary studies. The different proportions of arithmetic required in the different cases will force this upon the mind at once. Elsewhere in the report it is taken as an accepted rule that more cultivated fitness is required to teach a primary than a model school. 
The number of females attending the second-grade schools is equal to the number of males, and three-fifths of the teachers also in these schools are women. So many important institutions having for their main object the higher education of the sex have been opened in the United States that it is considered that the special examinations of females conducted for some time past under the auspices of the Harvard University may now be dropped. The number of them competing for scholastic honours on the same basis as the men is steadily increasing; "but," the report suggestively adds, "not rapidly enough to threaten any disturbance of existing social, domestic, or business relations."

One association for promoting the higher education of women reports that while the physique of lady students is higher than among women at large, yet that even that of the former is painfully low, and requires that measures should be taken against so dangerous a deterioration.

With regard to the co-education of men with women, a committee, appointed by a Western College to inquire into the subject, conclude by saying:-

"Joint education of men with women in the higher studies has now been tried in a sufficient number and variety of colleges, and for a sufficient length of time to prove that no special difficulties and evils grow out of it, and that it does away with the greatest difficulties and evils of the old monastic system. It makes college life and society more nearly human instead of only 'halfhuman.' The half-human ever verges first and last towards the bestial, whether in armies, on shipboard, in miners' camps, or in colleges, monasteries, or nunneries. It would be wise to humanise the colleges still more, rather than to begin the process of dehumanising them."

It is then urged that all lectures and studies should be conducted in as public a manner as possible, and attended by friends and relations of both sexes.

Kindergarten teaching is being carried out more largely, but is making its way more as a charitable institution than as a branch of education. Very appropriately it is becoming the ladies' charity ; its work is found specially beneficial as the early beginning of a reformatory education for the purpose of overcoming inherited vicious propensities and physical infirmities. Most energetic efforts for this purpose are being made at San Francisco in particular.

Attention is specially called in this report to the desirability of teaching history so as to make the reading of it an intelligent study, attractive to its learners, who will fill up leisure time with its pursuit instead of, as of old, insisting on the laying to heart long tables of dates and dry facts, "killing the life out of the subject, disgusting the pupils, and giving them a dislike for historical reading."

Colleges of the highest class keep increasing in number, yet, nevertheless, the totals of teachers and pupils are small for the proud name each claims of "University." Some have resigned that title and devoted themselves to school work ; but more fresh ones have sprung up which constitute a splendid force for future generations when their work, their wealth, and the population supporting them, have been multiplied. The fact of a superabundance of such institutions proves how highly learning even of the least utilitarian character is esteemed.

Perhaps traceably to temporary reasons, classics seem to be gaining rather than losing ground upon physica science at Harvard, a higher standard of instruction ard attainment having been required in the latter. Technical schools, however, make steady, though not rapid, progress. Agriculture, mining, and building form so large a proportion of American employment that full attention can be given to these subjects with little besitation. The bulk of their pupils are at once absorbed in further teaching, instead of putting into practice what they know, with their own hands.
The United States Commissioner of Education takes an annual survey of the whole educational world, and presents it to all who study his report, and when the subjects to be taught a different people like the 200,000,000 of British India are in it placed side by side with those which seem important in our own schools, a question suggests itself whether scientific teachings have not a better claim than the old knowledge to the title of "literæ humaniores." We see how local and confined are classical and historical studies, and of what common value to the whole human race are the elements of natural and physical science.

The free education which Texas and others of the United States are in favour of is not recommended by our Commissioners even in a country where it would interfere with so few vested interests as in India.

We are glad to know that a work on public libraries is progressing, which is intended to supplement the special report published in 1876 .

There are 11,663 institutions in regular correspondence with the Bureau, and no one reading this report can fail to see the importance of a common centre of communication to so many and so various efforts to carry on the great work that will have such an influence over the next generation. A central nucleus, again, to this organisation must be a library, by reference to which inquiries from so many quarters on so many subjects may be answered. It is hard, therefore, to believe it a wise economy of a great nation to cut down the allowance for so permanent a part of the office as this from 1000 dollars to 500 dollars, which, nevertheless, has been done.

W. ODELL

\section{COLLECTION OF HAIRS AFTER EARTH-} QUAKES IN CHINA

I N Dr. Macgowan's "Note on Earthquakes in China," republished in NATURE for May 6 (p. 17), I find the following passage :-

"The tremors that are experienced in Chehkiang, Kiangsu, and coterminous regions to the west, are sometimes followed by the appearance on the ground of substances that in Chinese books are styled "white hairs., When I first called attention to records of that kind that are found in local gazetteers, I suggested that they might be crystals precipitated by gaseous emissions, such as were once reported as occurring after an earthquake in south-west of the United States; from later descriptions of these 'horsetail-like' substances I incline to the opinion that they are organic, perhaps mycelium."

I think there can be little doubt that Dr. Macgowan's conclusion is well founded, and that the "white hairs" have no real connection with the earthquake.

In 1852 , during one of the late Mr. Fortune's visits to China, he experienced the shock of an earthquake at Shanghai. He gives the following curious account in "A Residence among the Chinese" (pp. 4, 5), of the subsequent search for the hairs:-

"Groups of Chinese were seen in the gardens, roadsides, and fields engaged in gathering hairs which are said to make their appearance on the surface of the ground after an earthquake takes place. This proceeding attracted a great deal of attention from some of the foreign residents in Shanghai, and the Chinese were closely examined upon the subject. Most of them fully believed that these hairs made their appearance only after an earthquake had occurred, but could give no satisfactory explanation of the phenomenon, while some, more wise than their neighbours, did not hesitate to affirm that they belonged to some huge subterraneous animal whose slightest shake was sufficient to move the world.

"I must confess, at the risk of being laughed at, that I was one of those who took an interest in this curious subject, and that I joined several groups who were 